\title{
DIJAGRAMI INTERAKCIJE ZA ARMIRANOBETONSKI ŠUPLJI KRUŽNI POPREČNI PRESJEK
}

\author{
INTERACTION DIAGRAMS FOR REINFORCED \\ CONCRETE HOLLOW CIRCULAR CROSS-SECTION
}

\author{
Željko Smolčić́, Ksenija Blašković ${ }^{* *}$
}

\begin{abstract}
Sažetak
Opisan je postupak izrade dijagrama interakcije za armiranobetonske šuplje kružne poprečne presjeke prema normi HRN EN 1992-1-1. Zbog uvođenja novih razreda čvrstoće betona $s$ nešto drugačijim parametrima proračunskog dijagrama naprezanje-relativna deformacija, dolazi do potrebe izrade novih dijagrama interakcije. Proveden je postupak proračuna temeljem kojeg su izrađeni dijagrami interakcije za šuplji kružni poprečni presjek za razrede betona od C12/15 do C50/60. Primjenom dobivenih dijagrama interakcije pojednostavljuje se postupak dimenzioniranja armiranobetonskih šupljih kružnih poprečnih presjeka.
\end{abstract}

Ključne riječi: armirani beton, dimenzioniranje, šuplji kružni poprečni presjek, dijagrami interakcije

\begin{abstract}
The procedure for creating interaction diagrams for reinforced-concrete hollow circular cross sections, based on HRN EN 1992-1-1, is described in the paper. Due to introduction of new concrete strength classes, with somewhat different parameters for the stress-relative strain diagram, it has become necessary to develop new interaction diagrams. The computation procedure, based on which hollow circular cross section interaction diagrams were made for concrete classes from C12/15 to C50/60, was conducted. The use of these interaction diagrams will simplify dimensioning of reinforced-concrete hollow circular cross-sections.
\end{abstract}

\footnotetext{
*Građevinski fakultet Sveučilišta u Rijeci, Radmile Matejčić 3, 51000 Rijeka

E-mail: zeliko.smolcic@uniri.hr

${ }^{* *}$ Građevinski fakultet Sveučilišta u Rijeci, Radmile Matejčić 3, 51000 Rijeka

E-mail: ksenija.blaskovic@student.uniri.hr
} 
Key words: reinforced concrete, dimensioning, hollow circular cross-section, interaction diagrams

\section{Uvod}

Norma HRN EN 1992 [1] uvodi nove razrede čvrstoća betona; osim uobičajenih betona razreda $\mathrm{C} 12 / 15$ do razreda $\mathrm{C50} / 60$ uvode se i novi razredi betona: C55/67, C60/75, C70/85, C80/95 i C90/105. Poznato je su betoni velikih čvrstoća manje duktilni od betona uobičajenih čvrstoća, što ima za posljedicu mijenjanje oblika proračunskog dijagrama naprezanjerelativna deformacija za betone viših razreda. Normom HRN EN 1992 [1] veličina proračunske tlačne čvrstoće betona promijenila se u odnosu na prijašnju normu HRN ENV 1992 [2]. Zbog gore navedenih razloga, javlja se potreba za izradom novih dijagrama interakcije za dimenzioniranje armiranobetonskih kružnih šupljih poprečnih presjeka na savijanje s osnom silom.

Dijagrami interakcije kružnog šupljeg poprečnog presjeka koji omogućuju proračun prema normi HRN EN 1992-1-1 [1] i normi DIN 10451 [3] dostupni su u literaturi [4]. Proračunski dijagrami betona prema normama DIN 1045-1 [3] i HRN EN 1992-1-1 [1] identični su za betone razreda C12/15 do C50/60. Dijagrami interakcije kružnog šupljeg poprečnog presjeka prema normi DIN 1045-1 [3] mogu ponuditi približne vrijednosti, ali se u Hrvatskoj mogu koristiti uz određena ograničenja, budući da su određeni za proračunske dijagrame naprezanje-relativna deformacija čelika za armiranje s kosom gornjom granom u skladu s DIN 1045-1 [3]. Dijagrami interakcije dostupni u literaturi [4] napravljeni su za najveću relativnu deformaciju vlačne armature 0,025 (25\%), dok se u Hrvatskoj uobičajeno rabi $0,02(20 \%)$ [5]. Osim toga, za betone razreda višeg od C50/60 proračunski dijagrami betona i čelika prema normama DIN 1045-1 [3] i HRN EN 1992-1-1 [1] nisu identični, tako da se dijagrami interakcije prema DIN 1045-1 [3] u Hrvatskoj ne mogu koristiti.

Za izradu dijagrama interakcije korišten je računalni program MathCad 2001i [6]. Dijagrami interakcije dani u ovome radu izrađeni su u sklopu završnog rada [7].

U ovom radu dani su dijagrami interakcije kružnog šupljeg poprečnog presjeka prema normi HRN EN 1992-1-1 [1], za razrede betona od C12/15 do C50/60. Dijagrami interakcije za kružni šuplji poprečni presjek za betone razreda viših od C50/60 dani su u [7]. 


\section{Opis poprečnog presjeka}

Opis kružnog šupljeg poprečnog presjeka s armaturom prikazan je na Slici 1. Tlačna naprezanja i tlačne relativne deformacije dane u ovom radu uzimaju se s negativnim predznakom, dok se vlačna naprezanja i vlačne relativne deformacije uzimaju s pozitivnim predznakom.

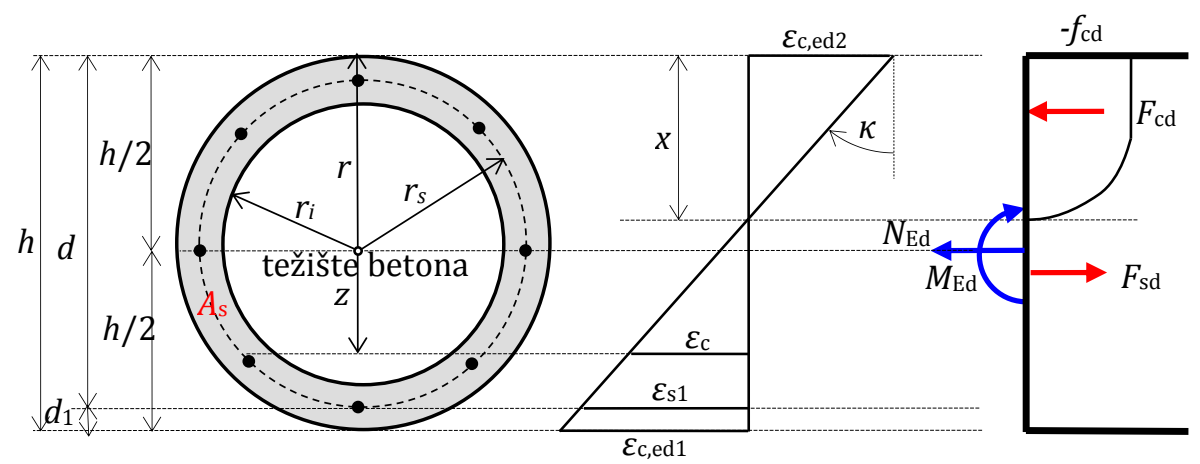

Slika 1. Kružni šuplji poprečni presjek s raspodjelom deformacija, naprezanja i sila

Deformacija betona u proizvoljnoj točki određuje se kao:

$$
\varepsilon_{\mathrm{c}}=\varepsilon_{\mathrm{c}, \mathrm{ed} 2}+\kappa\left(\frac{h}{2}+z\right) \text {. }
$$

Zakrivljenost poprečnog presjeka određuje se prema izrazu:

$$
\kappa=\frac{\varepsilon_{\mathrm{s} 1}-\varepsilon_{\mathrm{c}, \mathrm{ed} 2}}{d},
$$

gdje je:

$\varepsilon_{s 1} \quad$ - deformacije armature na donjem rubu,

$\varepsilon_{c, \text { ed2 }} \quad$ - deformacija betona na gornjem rubu,

$\varepsilon_{c, \text { ed1 }}$ - deformacija betona na donjem rubu,

$z$ - udaljenost od težišta betonskog presjeka do promatrane točke,

$h \quad$ - ukupna visina presjeka (promjer),

$d \quad$ - udaljenost gornjeg ruba betona do armature na donjem rubu,

$d_{1} \quad$ - udaljenost jednoliko raspoređene armature od ruba presjeka,

$x \quad$ - visina neutralne osi,

$r \quad$ - vanjski polumjer kružnog šupljeg poprečnog presjeka,

$r_{\mathrm{i}} \quad$ - unutarnji polumjer kružnog šupljeg poprečnog presjeka. 
Usvojena je pretpostavka da ravni presjeci i nakon deformacije presjeka ostaju ravni (Bernoullijeva hipoteza ravnih presjeka), što ima za posljedicu da će se sve točke deformiranog presjeka nalaziti u istoj ravnini (ravnini deformacije) koja prolazi kroz neutralnu os presjeka i koja je pod nagibom $\kappa$ na nedeformiranu ravninu presjeka.

Armatura je jednoliko raspoređena na kružnici radijusa $r_{\mathrm{s}}$ od težišta presjeka betona. Deformacija armature u proizvoljnoj točki kružnice određuje se prema izrazu (Slika 1 i 2):

$$
\varepsilon_{\mathrm{s}}=\varepsilon_{\mathrm{c}, \mathrm{ed} 2}+\kappa\left(\frac{h}{2}+z\right)=\varepsilon_{\mathrm{c}, \mathrm{ed} 2}+\kappa\left(\frac{h}{2}+r_{\mathrm{s}} \cdot \cos \alpha\right),
$$

gdje su $r_{\mathrm{s}}$ i $\alpha$ definirani na slici 1 i 2 .

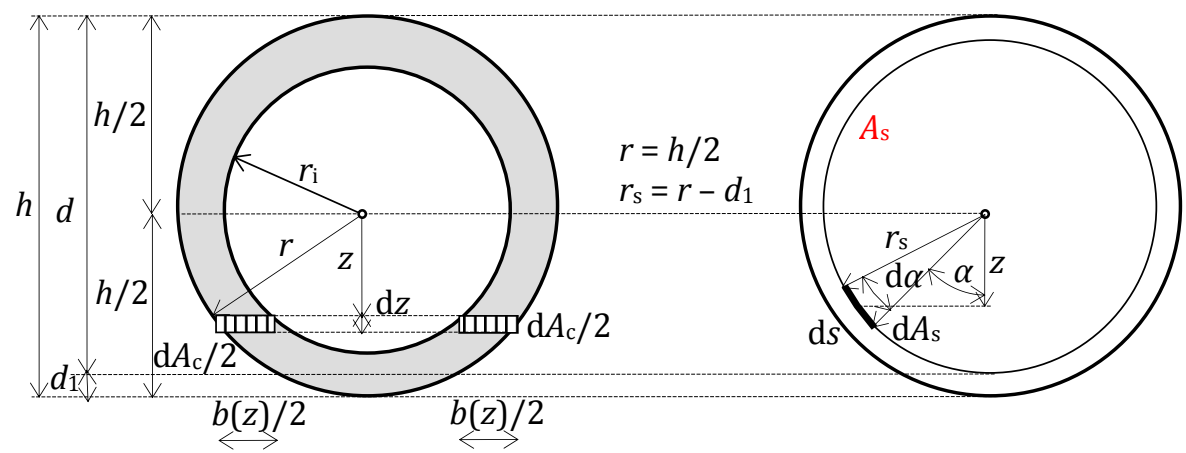

Slika 2. Diferencijalne površine betona i armature

Za definiranje ravnine deformacije potrebno je poznavati samo dvije od triju vrijednosti $\left(\varepsilon_{c, \text { ed2 }}, \varepsilon_{s 1}\right.$ i $\kappa$ ), što je vidljivo iz izraza (2). Pri konstruiranju dijagrama interakcije dvije od ovih vrijednosti $\left(\varepsilon_{c, \text { ed2 }}, \varepsilon_{s 1}\right)$ treba varirati, dok se treća veličina $\kappa$ dobiva iz izraza (2).

Pomoću dijagrama interakcije moguće je dimenzioniranje presjeka napregnutih tlačnom ili vlačnom osnom silom s momentom savijanja. Osim toga, dijagrami interakciji mogu se koristiti za dimenzioniranje presjeka napregnutih savijanjem bez osne sile i presjeka napregnutih samo osnom silom. Područja položaja ravnine deformacije općeg poprečnog presjeka prikazana su na Slici 3 [1]. 


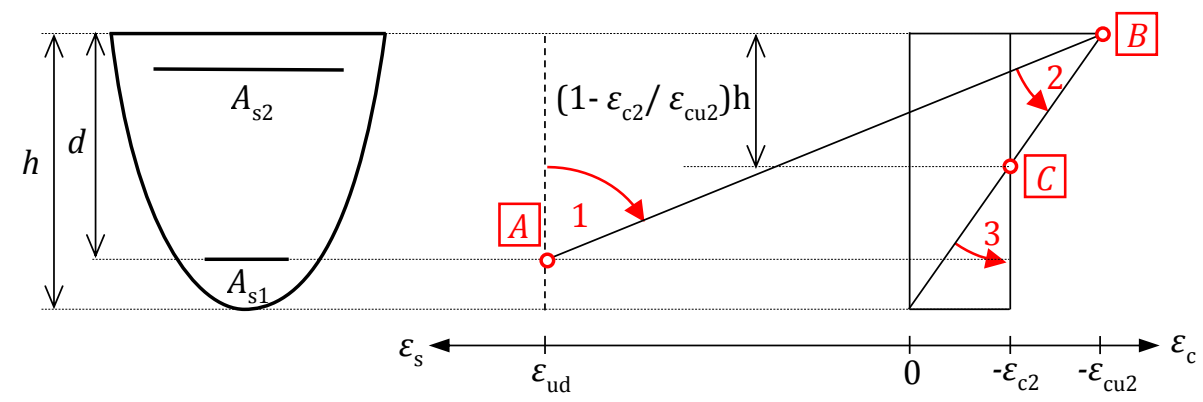

Slika 3. Moguće raspodjele deformacija u armiranobetonskom presjeku općeg oblika prema [1]

Položaji ravnine deformacije varirani su rotacijom ravnine deformacije oko osi koje su paralelne s neutralnom osi presjeka te prolaze kroz točke A, B ili C (Slika 3.):

Područje 1 (rotacija oko točke A)

$\varepsilon_{\mathrm{s} 1}=\varepsilon_{\mathrm{ud}}$

$\varepsilon_{\mathrm{c}, \mathrm{ed} 2}$ varira se od $\varepsilon_{\mathrm{ud}}$ do $-\varepsilon_{\mathrm{cu} 2}$

Područje 2 (rotacija oko točke B)

$\varepsilon_{\mathrm{c}, \mathrm{ed} 2}=-\varepsilon_{\mathrm{cu} 2}$

$\varepsilon_{\mathrm{s} 1}$ varira se od $\varepsilon_{\mathrm{ud}}$ do $\left(-\varepsilon_{\mathrm{cu} 2} / h\right) \cdot d_{1}$

Područje 3 (rotacija oko točke $C$ )

$\varepsilon_{\mathrm{c}, \mathrm{ed} 2}$ varira se od $-\varepsilon_{\mathrm{cu} 2}$ do $-\varepsilon_{\mathrm{c} 2}$

$\varepsilon_{\mathrm{s} 1}$ varira se od $\left(-\varepsilon_{\mathrm{cu} 2} / h\right) \cdot d_{1}$ do $-\varepsilon_{\mathrm{c} 2}$

Širina betonskog presjeka dobije se prema Slici $2 .:$

$$
\begin{array}{ll}
b(z)=2 \sqrt{r^{2}-z^{2}} & \text { za }-r \leq z \leq-r_{\mathrm{i}}, \\
b(z)=2 \sqrt{r^{2}-z^{2}}-2 \sqrt{r_{\mathrm{i}}^{2}-z^{2}} & \text { za }-r_{\mathrm{i}}<z<r_{\mathrm{i},} \\
b(z)=2 \sqrt{r^{2}-z^{2}} & \text { za } r_{\mathrm{i}} \leq z \leq r,
\end{array}
$$

Diferencijalna površina betona dobije se prema Slici 2:

$d A_{\mathrm{c}}=b(z) \cdot d z$. 
Diferencijalna površina armature određuje se prema Slici 2 , uz pretpostavku da je armatura jednoliko raspoređena na udaljenosti $r_{\mathrm{s}}$ od težišta presjeka betona:

$$
d A_{\mathrm{s}}=\frac{A_{\mathrm{s}}}{2 \cdot r_{\mathrm{s}} \cdot \pi} d s=\frac{A_{\mathrm{s}}}{2 \cdot r_{\mathrm{s}} \cdot \pi}\left(r_{\mathrm{s}} \cdot d \alpha\right)=\frac{A_{\mathrm{s}}}{2 \cdot \pi} d \alpha
$$

\section{Proračunski dijagrami}

\subsection{Proračunski dijagram betona}

Prema normi HRN EN 1992-1-1 [1], vrijednost proračunske tlačne čvrstoće određuje se izrazom:

$$
f_{\mathrm{cd}}=\alpha_{\mathrm{cc}} \cdot f_{\mathrm{ck}} / \gamma_{\mathrm{C}},
$$

gdje je $f_{\text {ck }}$ karakteristična tlačna čvrstoća betona, $\gamma_{C}$ parcijalni koeficijent sigurnosti za beton, a $\alpha_{c c}$ koeficijent kojim se u obzir uzimaju dugotrajni učinci na tlačnu čvrstoću i nepovoljni učinci koji su posljedica načina opterećivanja. Prihvaćena vrijednost u hrvatskom nacionalnom dodatku norme HRN EN 1992-1-1 [1] je $\alpha_{\text {cc }}=1,0$.

Za dimenzioniranje poprečnih presjeka na savijanje s osnom silom rabi se odnos naprezanje-relativna deformacija betona, prikazan na Slici 4 . Značajke betona prikazane su u Tablici 1 [1]. Naprezanje u betonu može se prikazati sljedećim izrazima:

$$
\begin{array}{ll}
\sigma_{\mathrm{c}}=-f_{\mathrm{cd}}\left[1-\left(1-\frac{\left|\varepsilon_{\mathrm{c}}\right|}{\varepsilon_{\mathrm{c} 2}}\right)^{\mathrm{n}}\right] & \text { za }-\varepsilon_{\mathrm{c} 2} \leq \varepsilon_{\mathrm{c}} \leq 0, \\
\sigma_{\mathrm{c}}=-f_{\mathrm{cd}} & \text { za }-\varepsilon_{\mathrm{cu} 2} \leq \varepsilon_{\mathrm{c}}<-\varepsilon_{\mathrm{c} 2}, \\
\sigma_{\mathrm{c}}=0 \mathrm{MPa} & \text { za } \varepsilon_{\mathrm{c}}>0,
\end{array}
$$

gdje je $n$ eksponent, $\varepsilon_{\mathrm{c} 2}$ je deformacija kad je dosegnuta čvrstoća betona, dok je $\varepsilon_{\text {cu2 }}$ krajnja deformacija (Tablica 1.). 


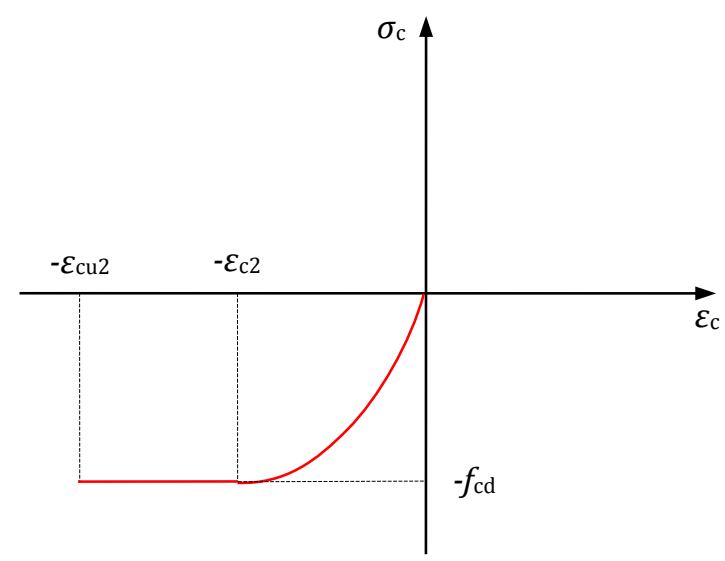

Slika 4. Dijagram naprezanje-relativna deformacija za beton

Tablica 1. Značajke betona prema HRN EN 1992-1-1

\begin{tabular}{|l|c|c|c|c|c|c|}
\hline & $\begin{array}{c}\text { C12/15- } \\
\text { C50/60 }\end{array}$ & C55/67 & C60/75 & C70/85 & C80/95 & C90/105 \\
\hline $\begin{array}{l}f_{\mathrm{ck}} \\
(\mathrm{MPa})\end{array}$ & 12 do 50 & 55 & 60 & 70 & 80 & 90 \\
\hline$\varepsilon_{\mathrm{c} 2}(\% 0)$ & 2,0 & 2,2 & 2,3 & 2,4 & 2,5 & 2,6 \\
\hline$\varepsilon_{\mathrm{cu} 2}(\% 0)$ & 3,5 & 3,1 & 2,9 & 2,7 & 2,6 & 2,6 \\
\hline$n$ & 2,0 & 1,75 & 1,6 & 1,45 & 1,4 & 1,4 \\
\hline
\end{tabular}

\subsection{Proračunski dijagram čelika za armiranje}

Prema normi HRN EN 1992-1-1 [1], za dimenzioniranje presjeka može se koristiti dijagram naprezanje-relativna deformacija za čelik za armiranje $\mathrm{s}$ horizontalnom gornjom granom bez potrebe ograničenja deformacije. Za konstruiranje dijagrama interakcije koji se prikazuju u ovom radu upotrijebljen je proračunski dijagram naprezanje-relativna deformacija za čelik za armiranje $\mathrm{s}$ horizontalnom gornjom crtom $\mathrm{s}$ najvećom deformacijom $\varepsilon_{\text {ud }}=0.02(20 \%)$ (Slika 5).

Na Slici $5 f_{\text {yk }}$ je karakteristična granica popuštanja čelika za armiranje, $f_{\text {yd }}$ je proračunska granice popuštanja čelika za armiranje a $\gamma_{S}$ je parcijalni koeficijent za čelik za armiranje. 


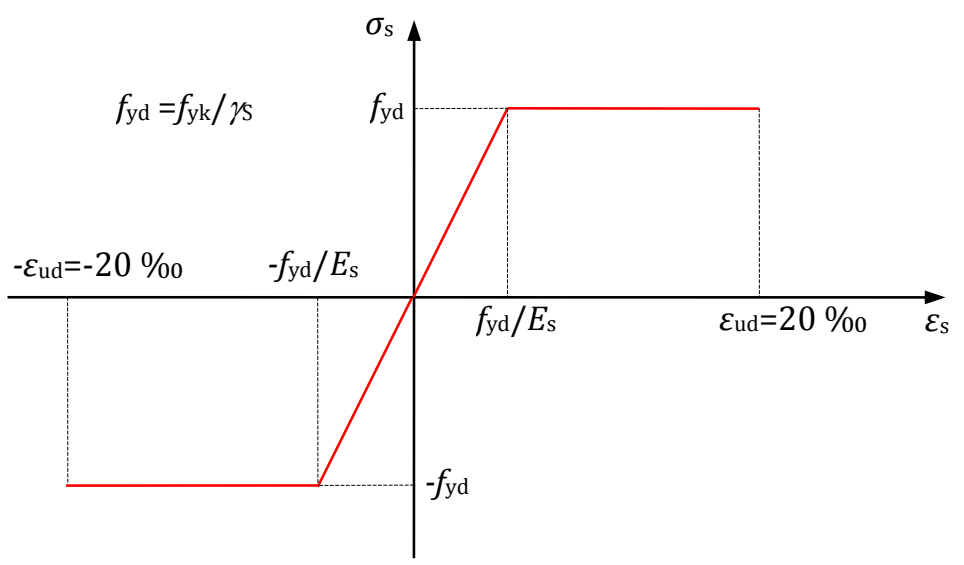

Slika 5. Dijagram naprezanje-relativna deformacija za čelik za armiranje

Naprezanje u armaturi (prema Slici 5) iznosi:

$$
\begin{array}{ll}
\sigma_{\mathrm{s}}=-f_{\mathrm{yd}} & \text { za }-\varepsilon_{\mathrm{udd}} \leq \varepsilon_{\mathrm{s}} \leq-\varepsilon_{\mathrm{yd}}, \\
\sigma_{\mathrm{s}}=\varepsilon_{\mathrm{s}} \cdot E_{\mathrm{s}} & \text { za }-\varepsilon_{\mathrm{yd}}<\varepsilon_{\mathrm{s}}<\varepsilon_{\mathrm{yd}}, \\
\sigma_{\mathrm{s}}=f_{\mathrm{yd}} & \text { za } \varepsilon_{\mathrm{yd}} \leq \varepsilon_{\mathrm{s}} \leq \varepsilon_{\mathrm{ud}},
\end{array}
$$

gdje je modul elastičnosti čelika $E_{\mathrm{s}}=200000 \mathrm{MPa}$, a $f_{\mathrm{yd}}$ proračunska granica popuštanja armature.

\section{Jednadžbe ravnoteže}

Proračunska tlačna sila u betonu određuje se prema izrazu:

$$
F_{\mathrm{cd}}=\int_{\AA_{\mathrm{c}}} \sigma_{\mathrm{c}} \cdot d A_{\mathrm{c}}=\int_{-\mathrm{h} / 2}^{\mathrm{h} / 2} \sigma_{\mathrm{c}} \cdot b(z) \cdot d z .
$$

Proračunska sila u armaturi proračunava se s pomoću izraza:

$$
F_{\mathrm{sd}}=\int_{\mathrm{A}_{\mathrm{s}}} \sigma_{\mathrm{s}} \cdot d A_{\mathrm{s}}=\int_{0}^{2 \cdot \pi} \sigma_{\mathrm{s}} \cdot\left(\frac{A_{\mathrm{s}}}{2 \cdot \pi} d \alpha\right),
$$

gdje je $A_{\mathrm{s}}$ ukupna površina presjeka armature. 
U presjecima istodobno naprezanim momentom savijanja i osnom silom potrebno je simultano zadovoljiti dva uvjeta:

$$
\begin{aligned}
& N_{\mathrm{Ed}} \leq N_{\mathrm{Rd}}, \\
& M_{\mathrm{Ed}} \leq M_{\mathrm{Rd}},
\end{aligned}
$$

gdje je:

$N_{\text {Ed }} \quad$ - proračunska djelujuća osna sila,

$M_{\text {Ed }} \quad$ - proračunski djelujući moment savijanja,

$N_{\mathrm{Rd}} \quad$ - otpornost presjeka na djelovanje osne sile,

$M_{\mathrm{Rd}} \quad$ - moment nosivosti presjeka.

Otpornost presjeka na djelovanje osne sile iznosi:

$$
N_{\text {Rd }}=F_{\text {cd }}+F_{\text {sd }} \text {. }
$$

Kada se izraz (20) uvrsti u izraz (18) dobije se:

$$
N_{\text {Ed }} \leq F_{\text {cd }}+F_{\text {sd }} \text {, }
$$

odnosno kada se u prethodni izraz (21) uvrste izrazi (16) i (17) za $F_{\text {cd }}$ i $F_{\text {sd }}$ dobiva se:

$$
N_{\text {Ed }} \leq \int_{-\mathrm{h} / 2}^{\mathrm{h} / 2} \sigma_{\mathrm{c}} \cdot b(z) \cdot d z+\int_{0}^{2 \cdot \pi} \sigma_{\mathrm{s}} \cdot\left(\frac{A_{\mathrm{s}}}{2 \cdot \pi} d \alpha\right) .
$$

Kada se izraz (22) podijeli faktorom $A_{\mathrm{c}} \cdot f_{\mathrm{cd}}$, dobiva se:

$$
\frac{N_{\mathrm{Ed}}}{A_{\mathrm{c}} \cdot f_{\mathrm{cd}}} \leq \frac{\int_{-\mathrm{h} / 2}^{\mathrm{h} / 2} \sigma_{\mathrm{c}} \cdot b(z) \cdot d z}{A_{\mathrm{c}} \cdot f_{\mathrm{cd}}}+\frac{A_{\mathrm{s}} \cdot f_{\mathrm{yd}}}{A_{\mathrm{c}} \cdot f_{\mathrm{cd}}} \frac{\int_{0}^{2 \cdot \pi} \sigma_{\mathrm{s}} \cdot\left(\frac{1}{2 \cdot \pi} d \alpha\right)}{f_{\mathrm{yd}}},
$$

gdje je $A_{c}=r^{2} \pi-r_{\mathrm{i}}^{2} \pi$ površina betonskog poprečnog presjeka.

U izraz (23) uvode se bezdimenzijska veličina osne sile $v_{\text {Ed }}$ i mehanički koeficijent armiranja $\omega$.

$$
v_{\mathrm{Ed}}=\frac{N_{\mathrm{Ed}}}{A_{\mathrm{c}} \cdot f_{\mathrm{cd}}},
$$




$$
\omega=\frac{A_{\mathrm{s}} \cdot f_{\mathrm{yd}}}{A_{\mathrm{c}} \cdot f_{\mathrm{cd}}}
$$

te se za $N_{\mathrm{Ed}}=N_{\mathrm{Rd}}$ dobiva:

$$
v_{\mathrm{Ed}}=\frac{\int_{-\mathrm{h} / 2}^{\mathrm{h} / 2} \sigma_{\mathrm{c}} \cdot b(z) \cdot d z}{A_{\mathrm{c}} \cdot f_{\mathrm{cd}}}+\omega \frac{\int_{0}^{2 \cdot \pi} \sigma_{\mathrm{s}} \cdot\left(\frac{1}{2 \cdot \pi} d \alpha\right)}{f_{\mathrm{yd}}} .
$$

Moment nosivosti kojim se presjek odupire savijanju iznosi:

$$
M_{\mathrm{Rd}}=\int_{-\mathrm{h} / 2}^{\mathrm{h} / 2} \sigma_{\mathrm{c}} \cdot z \cdot b(z) \cdot d z+\int_{0}^{2 \cdot \pi} \sigma_{\mathrm{s}} \cdot z \cdot\left(\frac{A_{\mathrm{s}}}{2 \cdot \pi} d \alpha\right)
$$

odnosno:

$$
M_{\mathrm{Rd}}=\int_{-\mathrm{h} / 2}^{\mathrm{h} / 2} \sigma_{\mathrm{c}} \cdot z \cdot b(z) \cdot d z+\int_{0}^{2 \cdot \pi} \sigma_{\mathrm{s}} \cdot\left(r_{\mathrm{s}} \cdot \cos \alpha\right) \cdot\left(\frac{A_{\mathrm{s}}}{2 \cdot \pi} d \alpha\right) .
$$

Kada se izraz (29) uvrsti u izraz (19) dobije se:

$$
M_{\mathrm{Ed}} \leq \int_{-\mathrm{h} / 2}^{\mathrm{h} / 2} \sigma_{\mathrm{c}} \cdot z \cdot b(z) \cdot d z+\int_{0}^{2 \cdot \pi} \sigma_{\mathrm{s}} \cdot\left(r_{\mathrm{s}} \cdot \cos \alpha\right) \cdot\left(\frac{A_{\mathrm{s}}}{2 \cdot \pi} d \alpha\right),
$$

a zatim se izraz (30) podijeli faktorom $A_{\mathrm{c}} \cdot h \cdot f_{\mathrm{cd}}$ :

$$
\frac{M_{\mathrm{Ed}}}{A_{\mathrm{c}} \cdot h \cdot f_{\mathrm{cd}}} \leq \frac{\int_{-\mathrm{h} / 2}^{\mathrm{h} / 2} \sigma_{\mathrm{c}} \cdot z \cdot b(z) \cdot d z}{A_{\mathrm{c}} \cdot h \cdot f_{\mathrm{cd}}}+\frac{A_{\mathrm{s}} \cdot f_{\mathrm{yd}}}{A_{\mathrm{c}} \cdot f_{\mathrm{cd}}} \cdot \frac{\int_{0}^{2 \cdot \pi} \sigma_{\mathrm{s}} \cdot\left(r_{\mathrm{s}} \cdot \cos \alpha\right) \cdot\left(\frac{1}{2 \cdot \pi} d \alpha\right)}{h \cdot f_{\mathrm{yd}}} .
$$

U izraz (31) uvodi se mehanički koeficijent armiranja $\omega$ (izraz (25)) i bezdimenzijska veličina momenta savijanja $\mu_{\text {Ed }}$ :

$$
\mu_{\mathrm{Ed}}=\frac{M_{\mathrm{Ed}}}{A_{\mathrm{c}} \cdot h \cdot f_{\mathrm{cd}}},
$$

te se za $M_{\mathrm{Ed}}=M_{\mathrm{Rd}}$ dobiva algebarska veza između bezdimenzijske veličine momenta savijanja $\mu_{\text {Ed }}$ i mehaničkog koeficijenta armiranja $\omega$ : 


$$
\mu_{\mathrm{Ed}}=\frac{\int_{-\mathrm{h} / 2}^{\mathrm{h} / 2} \sigma_{\mathrm{c}} \cdot z \cdot b(z) \cdot d z}{A_{\mathrm{c}} \cdot h \cdot f_{\mathrm{cd}}}+\omega \cdot \frac{\int_{0}^{2 \cdot \pi} \sigma_{\mathrm{s}} \cdot\left(r_{\mathrm{s}} \cdot \cos \alpha\right) \cdot\left(\frac{1}{2 \cdot \pi} d \alpha\right)}{h \cdot f_{\mathrm{yd}}} .
$$

Potrebna se površina presjeka armature, jednoliko raspoređene na udaljenosti $r_{\mathrm{s}}$ od težišta presjeka betona, određuje s pomoću izraza:

$$
A_{\mathrm{s}}=\omega \frac{f_{\mathrm{cd}}}{f_{\mathrm{yd}}} A_{\mathrm{c}} .
$$

Dijagrami interakcije dobiveni su na način da su varirane deformacije čelika $\varepsilon_{s 1}$ i betona $\varepsilon_{c, \text { ed2 }}$ (zakrivljenost $\kappa$ ) i mehanički koeficijent armiranja $\omega$, te su proračunavane vrijednosti $\nu_{\text {Ed }}$ (27) i $\mu_{\text {Ed }}$ (33) koje su nanesene u koordinatni sustav $v_{\text {Ed }}-\mu_{\text {Ed. }}$. Dijagrami interakcije (Slika 6) izrađeni su za kružni šuplji poprečni presjek i za betone razreda C12/15 do C50/60, čelik B500 te za omjer $d_{1} / h=0,1$.

Jednadžbe ravnoteže (27) i (33) postavljene su na način da vrijede za sva tri područja ravnine deformacije poprečnog presjeka (Slika 3). Umjesto analitičkog rješavanja integrala u jednadžbama (27) i (33), u programu MathCad [6], korištena je numerička integracija.

Naprezanja betona $\sigma_{\mathrm{c}}$ u izrazima (27) i (33) integriraju se po cijeloj visini presjeka, to jest od $-h / 2$ do $h / 2$. Naprezanja armature $\sigma_{\mathrm{s}}$ u izrazima (27) i (33) integriraju se po cijeloj kružnici, to jest, od kuta $\alpha=0$ do $2 \pi$. Naprezanja u betonu određuju se prema izrazima (10) do (12), a naprezanja u čeliku prema izrazima (13) do (15). 


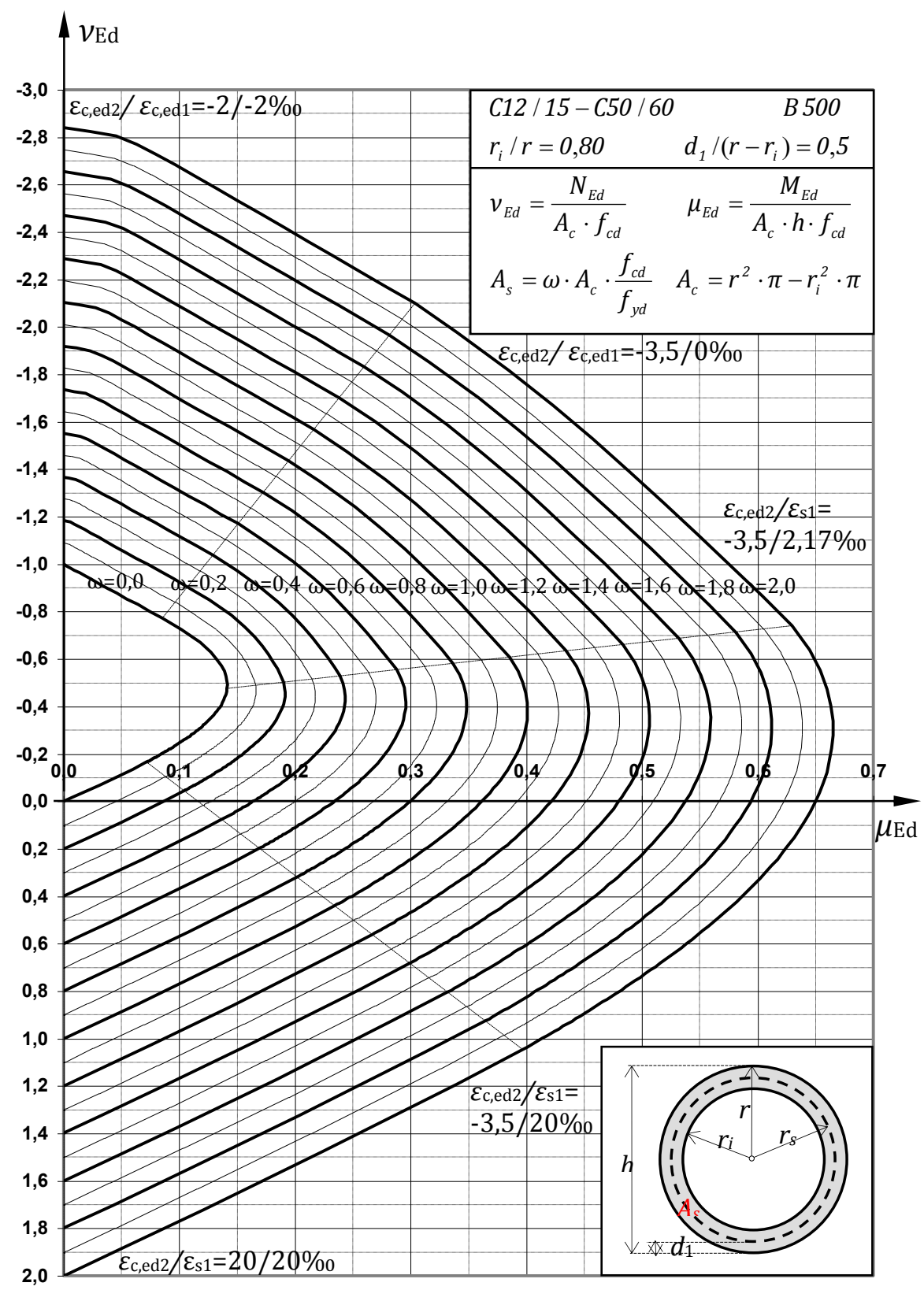

Slika 6. Dijagrami interakcije za kružni šuplji poprečni presjek C12/15 do C50/60, B500, $r_{i} / r=0,80, d_{1} /\left(r-r_{i}\right)=0,5$ 


\section{Numerički primjer}

Treba dimenzionirati kružni šuplji poprečni presjek stupa promjera $h=$ $100 \mathrm{~cm}(r=50 \mathrm{~cm})$ i unutarnjeg radijusa $r_{\mathrm{i}}=40 \mathrm{~cm}$, čija je armatura jednoliko raspoređena na udaljenosti $d_{1}=5 \mathrm{~cm}$ od ruba presjeka. Stup se predviđa izvesti od betona razreda C30/37, i čelika za armiranje B500B. Promatrani presjek napregnut je sljedećim proračunskim presječnim silama: $M_{\mathrm{Ed}}=1130,97 \mathrm{kNm}$ i $N_{\mathrm{Ed}}=-5654,87 \mathrm{kN}$.

Omjer:

$$
\frac{r_{\mathrm{i}}}{r}=\frac{40}{50}=0,8 \quad \frac{d_{1}}{r-r_{\mathrm{i}}}=\frac{5}{50-40}=0,5
$$

Proračunska tlačna čvrstoća betona:

$$
f_{\mathrm{cd}}=\alpha_{\mathrm{cc}} \frac{f_{\mathrm{ck}}}{\gamma_{\mathrm{C}}}=1,0 \cdot \frac{30}{1,5}=20 \mathrm{MPa}
$$

Proračunska granica popuštanja armature:

$$
f_{\mathrm{yd}}=\frac{f_{\mathrm{yk}}}{\gamma_{\mathrm{s}}}=\frac{500}{1,15}=434,78 \mathrm{MPa}
$$

Površina betonskog presjeka:

$$
A_{\mathrm{c}}=r^{2} \cdot \pi-r_{\mathrm{i}}^{2} \cdot \pi=50^{2} \cdot \pi-40^{2} \cdot \pi=2827,43 \mathrm{~cm}^{2}
$$

Bezdimenzijska veličina osne sile:

$$
v_{\mathrm{Ed}}=\frac{N_{\mathrm{Ed}}}{A_{\mathrm{c}} \cdot f_{\mathrm{cd}}}=\frac{-5654,87}{2827,43 \cdot 2,0}=-1,000
$$

Bezdimenzijska veličina momenta savijanja:

$$
\mu_{\mathrm{Ed}}=\frac{M_{\mathrm{Ed}}}{A_{\mathrm{c}} \cdot h \cdot f_{\mathrm{cd}}}=\frac{113097}{2827,43 \cdot 100 \cdot 2,0}=0,200
$$

Mehanički koeficijent armiranja očita se sa Slike 6:

$$
v_{\mathrm{Ed}}=-1,000, \mu_{\mathrm{Ed}}=0,200 \Rightarrow \omega=0,60
$$

Potrebna se površina armature, jednoliko raspoređena na udaljenosti $r_{\mathrm{s}}$ od težišta presjeka betona, određuje pomoću izraza:

$$
A_{\mathrm{s}}=\omega \frac{f_{\mathrm{cd}}}{f_{\mathrm{yd}}} A_{\mathrm{c}}=0,60 \frac{2,0}{43,478} 2827,43=78,04 \mathrm{~cm}^{2}
$$


U ovom primjeru nije se provjeravala minimalna i maksimalna armatura prema normi HRN EN 1992 [1].

Kontrola prikazanog primjera dimenzioniranja kružnog šupljeg presjeka provedena je s pomoću računalnog programa Gala Reinforcement $4.1 \mathrm{e}^{\odot}$ [8] i programa za dimenzioniranje armiranobetonskog kružnog šupljeg presjeka (program KP) [9]. Program Gala Reinforcement 4.1 $\mathrm{e}^{\odot}$ [8] služi za dimenzioniranje armiranobetonskih poprečnih presjeka proizvoljnih oblika naprezanih ravnim ili kosim savijanjem s osnom silom. Program KP [9] izrađen je s pomoću računalnog programa MathCad 2001i [6] u sklopu završnog rada [9] i služi za dimenzioniranje armiranobetonskih kružnih šupljih poprečnih presjeka naprezanih ravnim savijanjem s osnom silom.

Program Gala Reinforcement 4.1e ${ }^{\odot}$ [8] ne može se zadavati jednoliko raspoređena armatura već se armatura zadaje kao točkasta armatura, dok je programom KP [9] moguće zadavati jednoliko raspoređenu armaturu.

Vidljivo je da su rezultati dobiveni programom Gala Reinforcement 4.1 $\mathrm{e}^{\odot}$ [8] i programom KP [9] vrlo bliski (Tablica 2.). Razlika u dobivenim rezultatima pripisuje se različitom načinu definiranja razmještaja armature. Program Gala Reinforcement $4.1 \mathrm{e}^{\odot}$ [8] ne može zadavati jednoliko raspoređenu armaturu već se armatura zadaje kao točkasta armatura (u primjeru 36 šipki armature). Proračunata armatura u primjeru, uz primjenu dijagrama interakcije, zanemarivo je manja. To je posljedica korištenja dijagrama interakcije, kod kojih točnost proračuna ovisi o odoka očitanoj vrijednosti mehaničkog koeficijenta armiranja $\omega$. Razlika u rezultatima može biti posljedica različitog tretiranja betona na mjestu armature. Program Gala Reinforcement 4.1 $\mathrm{e}^{\odot}$ [8] i program KP [9] uzimaju u obzir da se na mjestu čelika za armiranje ne može nalaziti beton, dok kod dijagrama interakcije [7] ta pretpostavka ne vrijedi.

Tablica 2. Rezultati proračuna

\begin{tabular}{|l|l|l|l|}
\hline veličine & $\begin{array}{l}\text { dijagram } \\
\text { interakcije [7] }\end{array}$ & program KP [9] & program Gala [8] \\
\hline$A_{s}$ & $78,04 \mathrm{~cm}^{2}$ & $81,05 \mathrm{~cm}^{2}$ & $81,28 \mathrm{~cm}^{2}$ \\
\hline $\mathcal{E}_{\mathrm{c}, \mathrm{ed} 2}$ & $-3,50 \% 0$ & $-3,50 \% 0$ & $-3,50 \% 0$ \\
\hline$\varepsilon_{s 1}$ & oko $0,50 \% 0$ & $0,275 \% 0$ & $0,276 \% 0$ \\
\hline$x$ & & $88,07 \mathrm{~cm}$ & $88,05 \mathrm{~cm}$ \\
\hline
\end{tabular}




\section{Zaključak}

Prikazani su dijagrami interakcije za kružni šuplji poprečni presjek prema normi HRN EN 1992-1-1 za razrede betona od C12/15 do C50/60.

Dijagrami interakcije za kružni šuplji poprečni presjek dobiveni su na način da jednadžbe ravnoteže vrijede u svim područjima ravnine deformacije poprečnog presjeka i prilagođene su računalnim programima koji imaju mogućnost programiranja proračunskih procedura kao što je program MathCad.

Nedostatak opisanog postupka je relativno veliko vrijeme proračuna dijagrama interakcije zato što se, umjesto analitičkog rješevanja integrala, $u$ programu MathCad, koristila numerička integracija. S obzirom na brzinu današnjih osobnih računala to više ne predstavlja veliki problem.

S pomoću prikazanih dijagrama interakcije mogu se jednostavno, brzo i s dovoljnom točnošću dimenzionirati kružni šuplji armiranobetonski presjeci. Danas na raspolaganju postoje mnogi komercijalni računalni programski paketi s pomoću kojih se može provoditi proračun i automatsko dimenzioniranje armiranobetonskih konstrukcija, ali još uvijek postoji potreba za pomagalima za dimenzioniranje kao što su dijagrami interakcije.

Dijagrami interakcije mogu poslužiti kao kontrola dimenzioniranja provedenih pomoću komercijalnih programskih paketa u kojima su programirane procedure često podložne određenim pojednostavljenjima ili korisnicima programskih paketa nepoznatim interpretacijama normi i teorije armiranobetonskih konstrukcija od strane njihovih autora.

Prikazani postupak izrade dijagrama interakcije za kružni šuplji poprečni presjek može se primijeniti i za puni kružni poprečni presjek $\left(r_{\mathrm{i}}=0\right.$ m). Osim toga, prikazani postupak izrade dijagrama interakcije za kružni šuplji poprečni presjek može se, uz preradu, koristiti za bilo kakav poprečni presjek kod kojeg znamo funkciju promjene širine poprečnog presjeka $b(z)$.

\section{Literatura}

[1] HRN EN 1992-1-1, Eurokod 2. (2008) Projektiranje betonskih konstrukcija - 11. dio: Opća pravila i pravila za zgrade (EN 1992-1-1:2004+AC:2008) (prema EN1992-1-1:2004). Zagreb: HZN.

[2] HRN ENV 1992-1-1, Eurokod 2. (2004) Projektiranje betonskih konstrukcija 1-1. dio: Opća pravila i pravila za zgrade (prema ENV 1992-1-1:1991). Zagreb: HZN.

[3] DIN 1045-1. (2009) Tragwerke aus Beton, Stahlbeton und Spannbeton; Teil 1: Bemessung und Konstruktion. Betonkalender 2009. Berlin: Ernst \& Sohn. 
[4] Zilch, K., Zehetmaier, G. (2010) Bemessung im konstruktiven Betonbau Nach DIN 1045-1 (Fassung 2008) und EN 1992-1-1 (Eurocode 2). Berlin Heidelberg: Springer.

[5] Sorić, Z., Kišiček, T. (2014) Betonske konstrukcije 1. Zagreb: Građevinski fakultet Zagreb.

[6] Mathcad. (2001) User's Guide with Reference Manual Mathcad 2001i. MathSoft Engineering \& Education.

[7] Blašković, K. (2012) Dijagrami interakcije za kružni šuplji presjek. Završni rad. Rijeka: Građevinski fakultet Sveučilišta u Rijeci.

[8] Alashki, I. (2010) Računalni program Gala Reinforcement 4.1e. Sofija: Alashki.e.c Group.

[9] Peričić, L. (2017) Program za dimenzioniranje šupljeg kružnog presjeka, Završni rad. Rijeka: Građevinski fakultet Sveučilišta u Rijeci. 